\title{
Valve-in-valve transcatheter aortic valve implantation for failing surgical aortic stentless bioprosthetic valves: A single-center experience
}

\author{
Alison Duncan, MRCP, PhD, Simon Davies, MA, Carlo Di Mario, MD, PhD, and Neil Moat, MS, FRCS
}

\begin{abstract}
Background: Valve-in-valve (ViV) transcatheter aortic implantation (TAVI) is an alternative to redo surgery for patients with a failing aortic bioprosthesis. A lack of anatomic markers may complicate the procedure. This study reports procedural and midterm outcomes of patients undergoing ViV-TAVI for failing stentless bioprostheses, at a single institution.
\end{abstract}

Methods: A total of 22 consecutive patients with failing homograft $(n=17)$, stented porcine valve $(n=3)$, aortic root bioprosthesis $(n=1)$, or native resuspended aortic valve $(n=1)$ (aged $74 \pm 12$ years; Society of Thoracic Surgeons 30 -day predicted risk of mortality score: $14 \% \pm 8 \%$ ) were treated with $\mathrm{ViV}$ TAVI, between 2007 and 2014. All had severe aortic regurgitation and were highly symptomatic before TAVI: $41 \%$ had chronic kidney disease; 32\% had undergone previous coronary bypass grafts; $27 \%$ had previous percutaneous coronary intervention; $14 \%$ had severe pulmonary disease; $14 \%$ had had a stroke. All underwent TAVI with a self-expanding device.

Results: The 30-day mortality was $0 \%$. No cases occurred of myocardial infarction, tamponade, stroke, severe bleeding, acute kidney injury, or major vascular complications. Three instances of device migration, and 1 of device embolization, occurred. Permanent pacing was required in 14\%. Paravalvular aortic regurgitation was absent or mild in 19 , and mild to moderate in 3 . Average hospital stay was $8 \pm 3$ days; all patients were discharged home. Six-month and 1-year mortality was $4.8 \%$ and $14.3 \%$, respectively. Aortic valve area and paravalvular aortic regurgitation were unchanged at 1 year.

Conclusions: The ViV-TAVI procedure may be performed in high-risk patients with a degenerate stentless bioprosthesis with low 30-day mortality, and 1-year mortality of $14.3 \%$. Although technically challenging, owing to a lack of anatomic markers, satisfactory positioning is possible in most cases, with excellent clinical and echocardiographic outcomes. (J Thorac Cardiovasc Surg 2015;150:91-8)

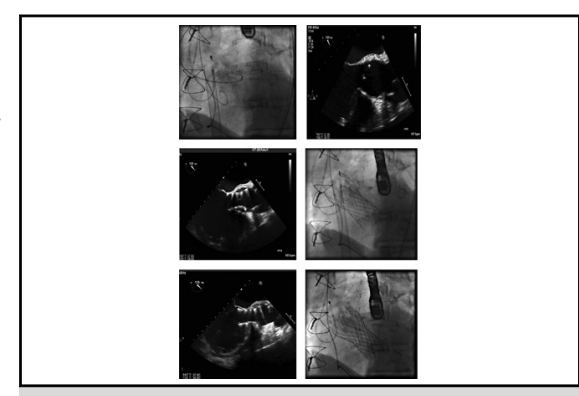

Lack of both calcification and a clear landing zone increases the risk of device migration during ViV-TAVI for degenerate, stentless, aortic valve replacement.

\section{Central Message}

Valve-in-valve TAVI in high-risk patients with degenerate stentless aortic bioprostheses has a 30 -day mortality of $0 \%$, and a 1 -year mortality of $14.3 \%$.

\section{Perspective}

The 2014 Valve-in-Valve International Data Registry included $<100$ patients with failing stentless aortic bioprostheses. We report procedural and midterm outcomes after ViV-TAVI from 22 high-risk patients (mean STS PROM score: $14 \% \pm 8 \%$ ) from a single center. Despite a lack of anatomic markers, lack of a clear landing zone, and difficulties with device sizing, satisfactory ViV-TAVI was possible. The 30 day mortality was $0 \%$, and 1 -year mortality was $14.3 \%$. More-than-mild paravalvular leak was present in $13 \%$ of patients, but average hospital stay was only $8 \pm 3$ days. At 1 year, all surviving patients were well and able to be independent in all activities of daily living. The lack of calcification and of a clear landing zone increases the risk of device migration during ViV-TAVI for degenerate stentless AVR.

See Editorial Commentary page 99
Bioprosthetic valves are frequently used in the surgical treatment of patients with aortic stenosis. However, these valves have limited durability. Reoperation is the current

\footnotetext{
From the Heart Division, The Royal Brompton Hospital, London, United Kingdom. Received for publication Dec 17, 2014; revisions received March 10, 2015; accepted for publication March 15, 2015; available ahead of print April 11, 2015.

Address for reprints: Alison Duncan, MRCP, $\mathrm{PhD}$, Heart Division, The Royal Brompton Hospital, Sydney St, London SW3 6NP, United Kingdom (E-mail: a.duncan@rbht. nhs.uk).

$0022-5223 / \$ 36.00$

Copyright (c) 2015 by The American Association for Thoracic Surgery

http://dx.doi.org/10.1016/j.jtcvs.2015.03.021
}

standard of care for a failing aortic bioprosthesis. However, "redo" surgery can be associated with substantial mortality and morbidity, particularly in elderly patients and those with significant comorbidities. ${ }^{1-5}$

"Valve-in-valve" (ViV) transcatheter aortic valve implantation (TAVI) has emerged as a less-invasive alternative to conventional redo surgery for bioprosthetic valve dysfunction. ${ }^{6-19}$ According to the latest Global Valve-inValve International Data (VIVID) Registry, ${ }^{20}$ most worldwide ViV-TAVI procedures have been performed in failing stented bioprosthetic valves. Fewer than 100 patients in this 


\section{Abbreviations and Acronyms \\ AVR = aortic valve replacement \\ EuroSCORE $=$ European System for Cardiac \\ Operative Risk Evaluation \\ MSCT = multislice computed tomography \\ STS PROM $=$ Society of Thoracic Surgeons 30- day predicted risk of mortality \\ TAVI $=$ transcatheter aortic valve implantation \\ VARC-2 = Valve Academic Research Consortium-2 \\ $\mathrm{ViV} \quad=$ valve-in-valve}

registry have had a ViV-TAVI for a failing stentless bioprosthesis. Several technical difficulties may be associated with ViV-TAVI for a degenerate stentless bioprostheses, notably the absence of radiopaque landmarks from a stent frame or sewing ring, the use of various implantation techniques among surgical operators, and proximity of the coronary ostia.

These factors increase the risk of complications such as device migration, embolization, and coronary obstruction. ${ }^{21}$ We have previously reported the early outcome of a small number of patients who underwent ViV-TAVI in failing homograft root replacements. ${ }^{22}$ In the current study, we report the demographics, procedural outcome, complications, and 1 -year follow up of a large series of consecutive patients undergoing ViV-TAVI for failing stentless bioprostheses.

\section{METHODS}

Twenty-two patients underwent ViV-TAVI for a failing stentless aortic bioprosthesis within the study period (October 2009 to June 2014). Patient baseline demographics, procedural, and 1-year outcome after ViV-TAVI were studied and retrospectively compared with the outcome of 20 patients with failing stentless aortic bioprostheses who underwent redo-AVR during the same study period. The Royal Brompton and Harefield Clinical Practice Committee approved the study protocol, and the study was performed in compliance with current United Kingdom Data Protection and Information Governance legislation. All subjects gave written, informed consent.

\section{Before the Procedure}

Multislice computed tomography (MSCT) was used to measure aortic annular dimensions (Figure 1, $A-D$ ) and evaluate the optimal access route for TAVI. ${ }^{23}$ The mean orthogonal aortic annular dimensions were $22 \mathrm{~mm}$ by $25 \mathrm{~mm}$, and the aortic annular perimeter was $79 \pm 7 \mathrm{~mm}$ (Table 1). Three-dimensional transesophageal echocardiography was used to confirm aortic annular and device size before valve deployment (Figure 1,E). The previous surgical operation note and device details (including manufacturer, model, and size of bioprosthesis [Table 1]) were specifically obtained. Data were collected prospectively in the form of the United Kingdom TAVI dataset, and submitted into the national United Kingdom TAVI Registry.

\section{Valve-in-Valve Transcatheter Aortic Valve Implantation Procedure}

A standard TAVI procedure with a CoreValve prosthesis (Medtronic, Minneapolis, Minn) was performed in all cases, the details of which are described elsewhere. ${ }^{15,17,22}$ The access route was transfemoral in 19 cases, subclavian in 2, and direct aortic in 1. Fluoroscopic images were obtained coaxial to the stentless AVR bioprosthesis in patients with valvular calcification (Figure 2, $A$ ). In the 3 patients in whom calcification was absent (Figure 2, B), we placed either 2 pigtails (Figure 2, $C$ ), or 1 pigtail and an Amplatz catheter (Boston Scientific, Marlborough, Mass) (Figure 2, D) in the noncoronary and left coronary sinuses, respectively, to aid delineation of the target landing zone. Balloon aortic valvuloplasty was avoided in all cases.

The initial two-thirds of the deployment was effected slowly, under rapid ventricular pacing, at 120 to 180 beats per minute (depending on the individual hemodynamic situation), to reduce cardiac output and provide stabilization of the device during deployment in the setting of severe aortic regurgitation. When two-thirds of the device had been deployed, the position of the device was confirmed by transoesophageal echocardiography before full deployment.

\section{Data Analysis}

Clinical endpoints were analyzed at 30 days and 1 year after ViV-TAVI, according to VARC-2 (Valve Academic Research Consortium-2) criteria. $^{24}$ Results are presented as mean (SD) for normally distributed continuous variables; median (interquartile range) for continuous variables without normal distribution; and number (percentage) for categoric data. Continuous variables were compared before and after ViV-TAVI, using paired Student $t$ tests. Differences in baseline characteristics between ViV-TAVI and AVR were tested using the unpaired $t$ test (continuous variables) or $\chi^{2}$ analysis or the Fisher exact test, as appropriate. Statistical analysis was performed using R Core Team 2013, R Version 3.0.2 (R Foundation for Statistical Computing, Vienna, Austria).

\section{RESULTS}

\section{Patient Characteristics}

Twenty-two patients (14 male) had ViV-TAVI for a failing stentless bioprosthesis during the study period (October 2009 to June 2014): 17 had undergone previous homograft aortic root replacement; 3 had undergone Toronto SPV (stented porcine valve) AVR (St Jude Medical, Inc, St Paul, Minn); 1 had a Freestyle aortic root bioprosthesis (Medtronic Inc, Minneapolis, Minn), and 1 had a valve-sparing aortic root replacement with resuspension of the native aortic valve (Table 1). The median time from AVR to ViV-TAVI was 15 years (range: 5-25 years). All patients had severe symptomatic aortic regurgitation and were in New York Heart Association class III or IV. Patients were elderly, with multiple comorbidities (Table 2) and high risk scores (a logistic European System for Cardiac Operative Risk Evaluation [EuroSCORE] of $38 \% \pm 18 \%$, and Society of Thoracic Surgeons 30-day predicted risk of mortality [STS PROM] score of $14 \%$ $\pm 8 \%$ ), and thus were considered to have "extreme risk" for surgery.

By comparison, 20 patients (18 male) underwent redo AVR for a failing stentless bioprosthesis during the same study period (18 of 20 because of severe aortic regurgitation). Redo AVR patients were younger $(P<.001)$, with a significantly lower logistic EuroSCORE and STS PROM scores $(P<.001)$ than patients undergoing ViV-TAVI (Table 2). 

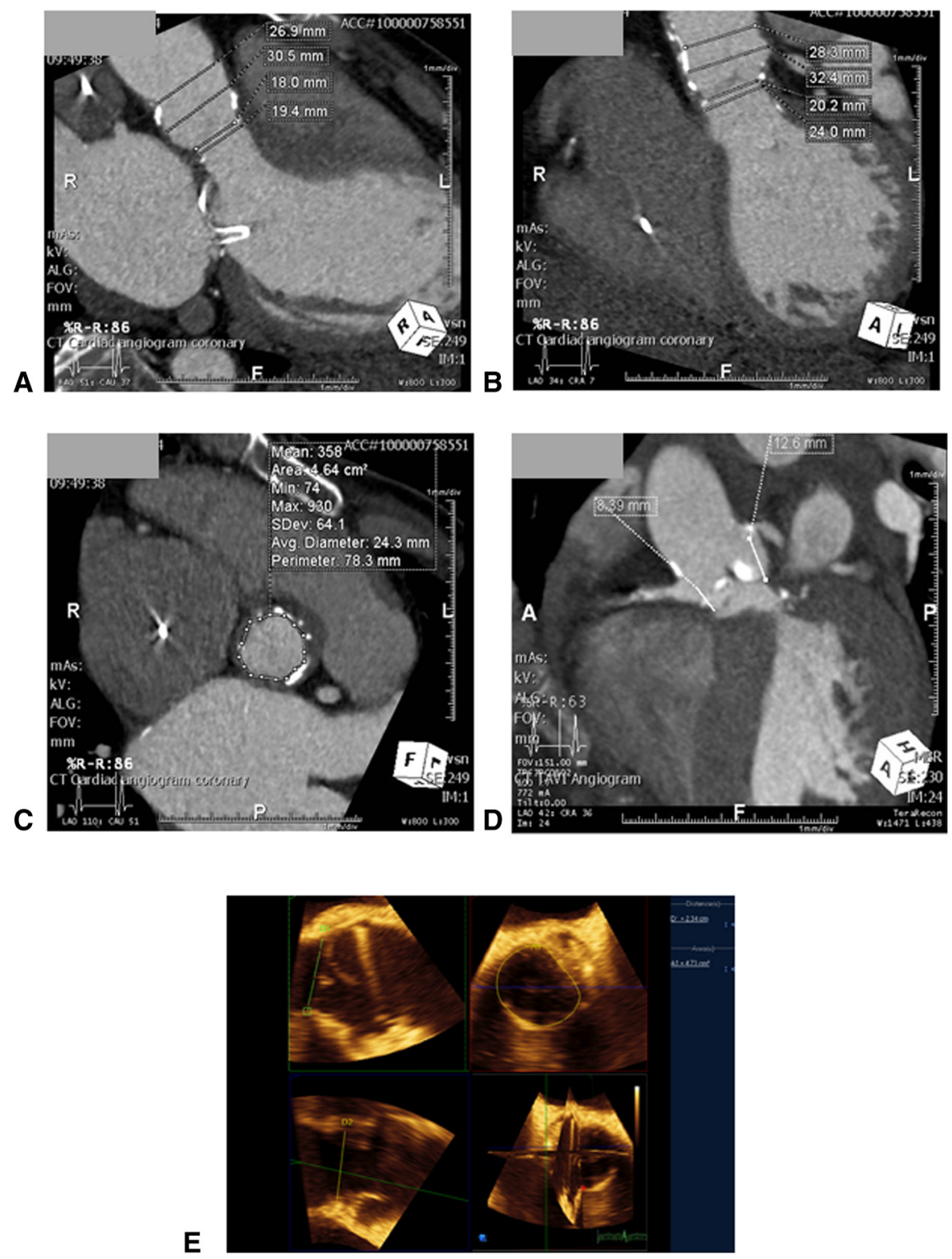

FIGURE 1. Multislice computed tomography was used to measure: (A and B) aortic annular dimensions in orthogonal planes; (C) the perimeter of the aortic annulus; and (D) the height of the coronary ostia. E, The perimeter of the aortic annulus was confirmed on 3-dimensional echocardiography. $R$, Right; $L$, left (also length); $A L G$, algorithm; FOV, field of view; $C T$, computed tomography; $F$, front; $A$, anterior; $w$, width; min, minimum; max, maximum.

\section{Procedural Results}

A CoreValve device was implanted in all 22 cases (23$\mathrm{mm}$ Evolut in 2 cases, a 26-mm device in 13 cases, a 29$\mathrm{mm}$ device in 6 cases, and a 31-mm device in the patient who had previously undergone aortic root replacement and resuspension of the native aortic valve). Our first ViVTAVI was performed as a salvage procedure in a patient in cardiogenic shock with severe aortic regurgitation secondary to a degenerated aortic valve homograft with recurrent ventricular tachycardia (STS PROM score: 42), who required extracorporeal circulatory support before and after the procedure. Thereafter, ViV-TAVI was performed electively in 7 patients, urgently in 13, and as an emergency in 1 (who had a left ventricular ejection fraction of $15 \%$, severe aortic regurgitation, severe mitral regurgitation, and severe right ventricular impairment). This latter patient underwent ViV-TAVI during a short period of elective cardiopulmonary bypass (Figure 1,C). By comparison, 15 of 20 redo AVR cases were performed electively.

Intraprocedural complications: Device positioning. A single transcatheter device was implanted during a single procedure into the correct anatomic location in 18 patients $(81.8 \%)$. A further 3 cases met the VARC-2 criteria for device migration. In 1 patient, the device moved in an aortic direction from its target implant position during deployment, and a second (more ventricular) device was implanted 
TABLE 1. Aortic annular dimensions and valve-in-valve transcatheter aortic valve implantation size

\begin{tabular}{|c|c|c|c|c|c|}
\hline Variable & $\begin{array}{l}\text { Annulus } \\
\text { diameter }\end{array}$ & $\begin{array}{c}\text { Annular } \\
\text { perimeter }\end{array}$ & $\begin{array}{c}\text { Implanted device } \\
\text { diameter }\end{array}$ & $\begin{array}{c}\text { Implanted device } \\
\text { perimeter, unconstrained }\end{array}$ & $\begin{array}{c}\text { Perimeter } \\
\text { oversizing }(\%)\end{array}$ \\
\hline 25-mm homograft & $25 \times 25$ & 87 & 29 & 91 & +4.4 \\
\hline 25-mm stented porcine valve & $24 \times 25$ & 86 & 29 & 91 & +5.5 \\
\hline 23-mm aortic root bioprosthesis & $22 \times 24$ & 78 & 26 & 82 & +4.9 \\
\hline 22-mm homograft & $20 \times 26$ & 79 & 26 & 82 & +3.7 \\
\hline 23-mm homograft & $21 \times 23$ & 77 & 26 & 82 & +6.1 \\
\hline 22-mm homograft & $21 \times 24$ & 78 & 26 & 82 & +4.9 \\
\hline 22-mm homograft & $19 \times 20$ & 79 & 26 & 82 & +3.7 \\
\hline 23-mm homograft & $21 \times 21$ & 72 & 26 & 82 & +12.1 \\
\hline 22-mm homograft & $21 \times 23$ & 77 & 26 & 82 & +6.1 \\
\hline Resuspension native aortic valve & $24 \times 26$ & 93 & 31 & 97 & +4.1 \\
\hline 22-mm homograft & $20 \times 24$ & 80 & 26 & 82 & +2.4 \\
\hline 23-mm aortic root bioprosthesis & $19 \times 23$ & 62 & 26 & 82 & +24.3 \\
\hline 25-mm homograft & $23 \times 25$ & 87 & 29 & 91 & +4.4 \\
\hline 25-mm homograft & $24 \times 24$ & 78 & 29 & 91 & +14.3 \\
\hline 22-mm homograft & $20 \times 20$ & 69 & 23 & 72 & +4.2 \\
\hline 20-mm homograft & $22 \times 24$ & 73 & 23 & 72 & -1.4 \\
\hline $25-\mathrm{mm}$ aortic root bioprosthesis & $23 \times 25$ & 80 & 26 & 82 & +2.4 \\
\hline 23-mm homograft & $25 \times 31$ & 91 & 29 & 91 & 0.0 \\
\hline 22-mm homograft & $21 \times 23$ & 68 & 26 & 82 & +20.1 \\
\hline 22-mm homograft & $22 \times 24$ & 74 & 26 & 82 & +9.8 \\
\hline 22-mm homograft & $22 \times 29$ & 86 & 26 & 82 & -4.9 \\
\hline $25-\mathrm{mm}$ homograft root & $27 \times 32$ & 92 & 31 & 97 & +5.2 \\
\hline
\end{tabular}

Values are given in $\mathrm{mm}$, unless otherwise indicated.

during the same procedure. In a second patient (who had previous aortic root replacement and resuspension of the native aortic valve), a 31-mm device was deployed too deep (ventricular) in the left ventricular outflow tract, and a second (more aortic) device was implanted during the same procedure.

In a third patient, the device was initially fully deployed at the correct level, but shortly afterward migrated down into the left ventricular outflow tract, and a second (higher) device was implanted during the same procedure (Figure 3, $A-C)$. A technical error occurred in 1 patient after correct initial device positioning. The device hooks were deemed to have been fully released from the delivery system, but 1 hook had not been released. When the delivery system was pulled back, the device embolized into the proximal ascending aorta. The patient required subsequent redoAVR and removal of the device, and had no long-term complications. Coronary ostial obstruction was not a feature in any case.

\section{Mortality Outcome}

No intraprocedural deaths occurred during ViV-TAVI, and the 30-day mortality rate was $0 \%$. The first (salvage) patient in the ViV-TAVI series (who was on circulatory support before and after the procedure) died 35 days after the procedure (of sepsis and multi-organ failure). Two other patients died within 12 months of ViV-TAVI (at 7 and 9 months, respectively, both from noncardiac causes). The overall 6-month mortality of the 21 patients who underwent
ViV-TAVI was $4.8 \%$; 1 -year mortality was $14.3 \%$. In the redo-AVR group, 1 patient died within 30 days of surgery (mortality: 5\%).

Clinical follow up at 30 days. Rates of myocardial infarction, cardiac tamponade, major vascular injury, major bleeding, bailout percutaneous coronary intervention, stroke, and dialysis were all $0 \%$ at 30 days. Three patients required permanent pacing ( 1 for new left bundle branch block, 2 for complete atrioventricular block). Fourteen had minor bleeding requiring a $\leq 2$-unit blood transfusion.

At 1 week, paravalvular leak was absent or trivial in 4 patients, mild in 15 patients, and mild to moderate in 3 patients (the first patient who underwent the procedure, under emergency conditions, the patient in whom the device embolized into the proximal ascending aorta as a result of a technical error, and the patient with a 22-mm homograft, in whom a $26-\mathrm{mm}$ device was implanted [ie, undersized by $4.9 \%$; Table 1]). Paravalvular leak was trivial or absent in the 3 patients who had valve migration initially, and who required a second ViV-TAVI during the same procedure. Peak and mean aortic pressure gradients fell compared with preTAVI levels (from $35 \pm 32$ to $22 \pm 15 \mathrm{~mm} \mathrm{Hg}, P=.046$, and from $21 \pm 17$ to $12 \pm 9 \mathrm{~mm} \mathrm{Hg}, P=.049$, respectively). The aortic valve area did not change (remaining at $2.0 \pm 0.7$ $\left.\mathrm{cm}^{2} ; P=.34\right)$.

Length-of-Stay and hospital discharge. All ViV-TAVI patients had immediate symptomatic improvement, moving from New York Heart Association class III (interquartile range: 1 ) at baseline to class I (interquartile range: 1 ) at 1 

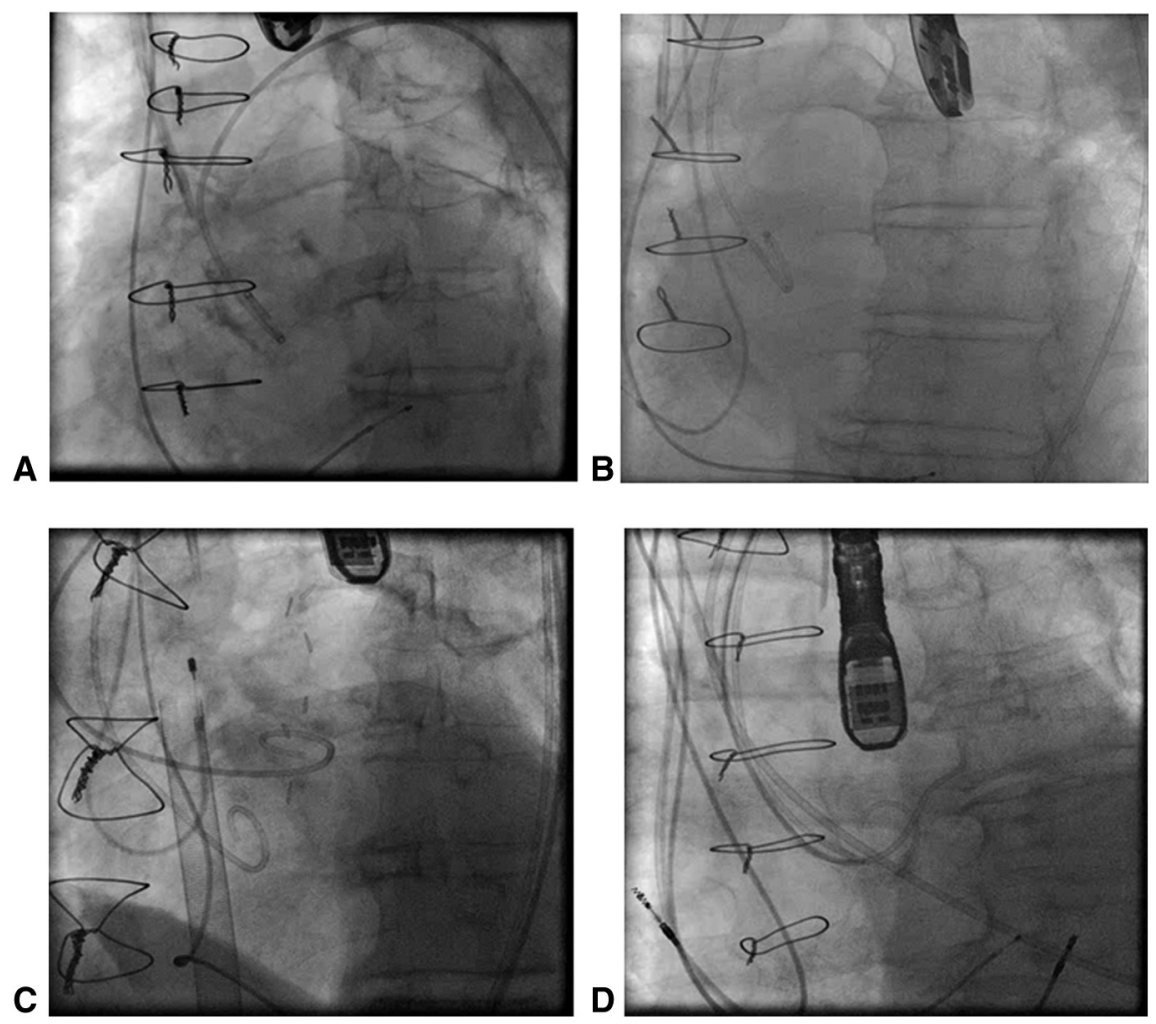

FIGURE 2. A, Calcification in stentless bioprostheses (A) can be used to identify the depth of valve implantation; but in some patients (B), no calcific landmarks are present to aid demarcation of the "landing zone." To identify the aortic annulus, 2 pigtails (C), or a pigtail and a catheter (D), can be placed in the coronary sinuses. In a clinically unstable patient, valve-in-valve transcatheter aortic valve implantation was performed using elective cardiopulmonary bypass (C).

week $(P .05)$. The average hospital stay was $8 \pm 3$ days (compared with $18 \pm 13$ days after redo-AVR, $P<.01$ ). All 21 patients surviving after ViV-TAVI were discharged directly home, and all were independently able to perform activities of daily living.

Long-Term follow up. Outcome data were available in all 18 patients who were alive at 12 months after ViV-TAVI. All had persistent improvement in symptoms (all were class I or II), with no signs of late valve migration, structural valve dysfunction, or change in the severity of paravalvular leak on echocardiography. The peak and mean aortic pressure gradients and aortic valve area remained unchanged, compared with 30 days post-TAVI $(19 \pm 16 \mathrm{~mm} \mathrm{Hg}, 10$ $\pm 7 \mathrm{~mm} \mathrm{Hg}$, and $1.6 \pm 0.4 \mathrm{~cm}^{2}$, respectively); left ventricular ejection fraction similarly showed no difference $(59 \%$ $\pm 8 \%$, compared with $55 \% \pm 16 \%, P=.48$ ). Brain naturetic peptide level, however, was significantly lower at 1 year, compared with that before ViV-TAVI (change from $515 \pm 366 \mathrm{nmol} / \mathrm{L}$ to $147 \pm 128 \mathrm{nmol} / \mathrm{L}, P<.001)$.

\section{DISCUSSION}

Although multiple studies demonstrate the feasibility of treating degenerate aortic valve bioprostheses with transcatheter valves, ${ }^{6-19}$ most report outcomes after ViV-TAVI for failure of stented bioprostheses. The latest report from the ViV International Data Registry included $<100$ patients who had a ViV-TAVI for a degenerate stentless bioprosthesis. $^{20}$ This study is significant in that it

TABLE 2. Patient demographics and investigations

\begin{tabular}{lcc}
\hline \multicolumn{1}{c}{ Variable } & TAVI $(\mathbf{n}=\mathbf{2 2})$ & Redo AVR $(\mathbf{n}=\mathbf{2 0})$ \\
\hline Age (range; y) & $74 \pm 14(25-88)$ & $53 \pm 14^{*}(43-71)$ \\
NYHA class III or IV & $22(100)$ & $17(85)$ \\
Atrial fibrillation & $10(45)$ & $3(15) \dagger$ \\
CKD (creatinine $>200 \mu \mathrm{mol} / \mathrm{L})$ & $9(41)$ & $2(10) \dagger$ \\
Asc. Aortic calcification & $8(36)$ & $0(0) \dagger$ \\
Previous CABG & $7(32)$ & $2(10)$ \\
Previous PCI & $6(27)$ & $2(10)$ \\
Peripheral vascular disease & $4(18)$ & $1(5)$ \\
COPD (TLCO $<30 \%)$ & $3(14)$ & $1(5)$ \\
Previous CVA & $3(14)$ & $0(0)$ \\
Logistic EuroScore $(\%)$ & $38 \pm 18$ & $15 \pm 15^{*}$ \\
STS PROM score $(\%)$ & $14 \pm 8$ & $6 \pm 2^{*}$ \\
\hline
\end{tabular}

Values are given as $\mathrm{n}(\%)$ or mean $\pm \mathrm{SD}$, unless otherwise indicated. TAVI, Transcatheter aortic valve implantation; $A V R$, aortic valve replacement; NYHA, New York Heart Association; $C K D$, chronic kidney disease; $A s c$., ascending; $C A B G$, coronary artery bypass graft; $P C I$, percutaneous coronary intervention; $C O P D$, chronic pulmonary obstructive disease; $T L C O$, total lung capacity; $C V A$, cerebrovascular accident; EuroSCORE, European System for Cardiac Operative Risk Evaluation; STS PROM, Society of Thoracic Surgeons predictor of mortality. $* P<.001 . \dagger P<.05 . \ddagger P<.01$. 

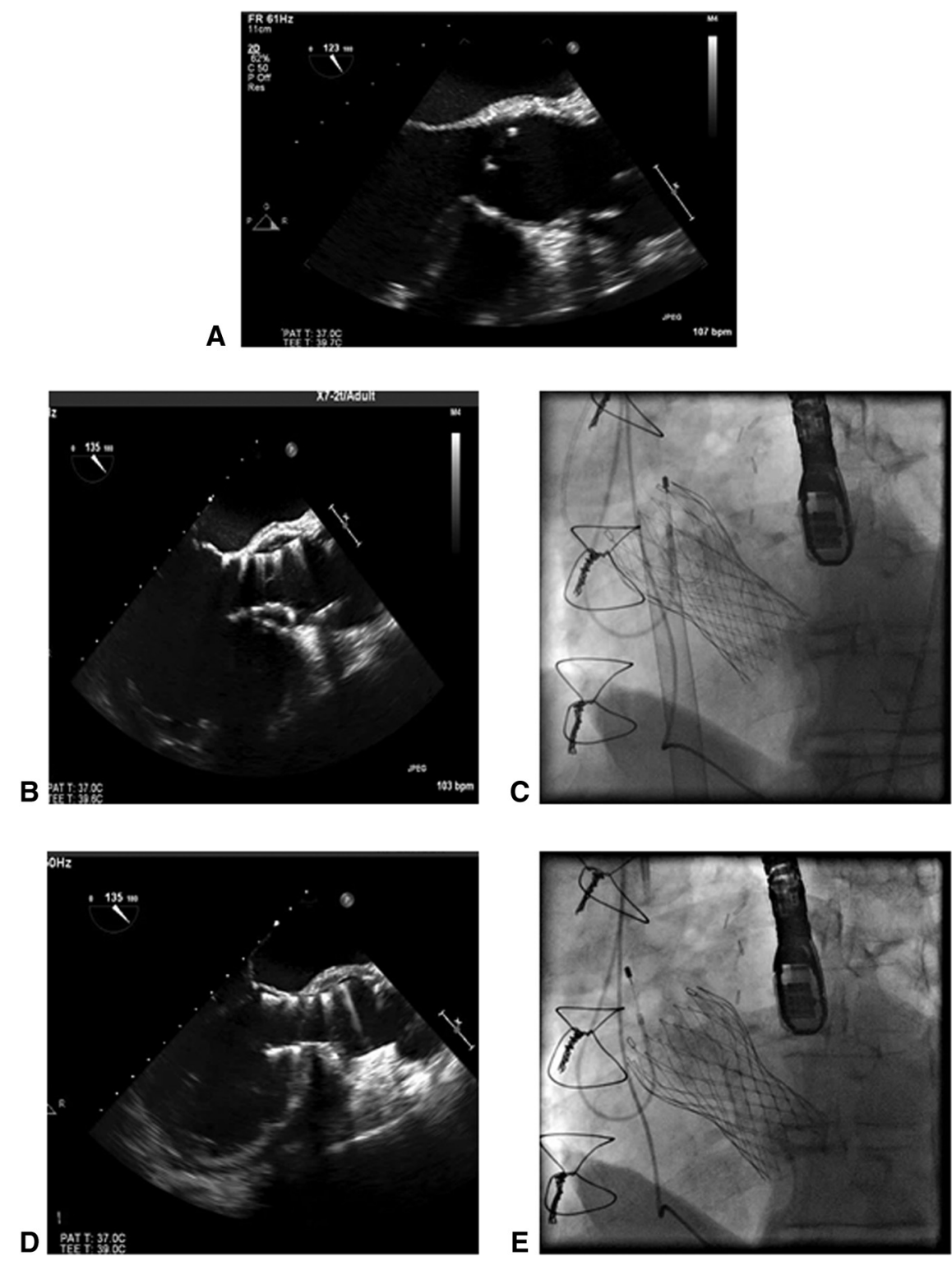

FIGURE 3. In a patient with a noncalcified failing homograft (A), a valve was successfully deployed in a good position on transesophageal echocardiography (B) and fluoroscopy (C), with only trivial paravalvular aortic regurgitation. One hour later, the device suddenly and unexpectedly dived down into the left ventricular outflow tract, with consequent severe paravalvular aortic regurgitation. A second device was required, implanted higher, during the same procedure. bpm, Beats per minute.

presents experience with ViV-TAVI for stentless failing bioprostheses.

\section{Principal Findings}

Patients who underwent ViV-TAVI were significantly older than patients undergoing redo-AVR, and they had more comorbidities, reflected in significantly higher surgical risk scores. All ViV-TAVI patients had structural stentless bioprosthetic degeneration, resulting in significant aortic regurgitation $^{25}$; all were highly symptomatic at presentation, and the majority of ViV-TAVI procedures were performed as urgent or emergency cases. By comparison, redo-AVR was performed electively in most cases.
Despite the fact that a high-risk group of patients was involved, 30-day mortality after ViV-TAVI was zero. In addition, mortality at 4 months and 1 year was low, at $4.8 \%$ and $14.3 \%$, respectively. None of the cases involved myocardial infarction, cardiac tamponade, vascular injury, stroke, gastrointestinal bleed, or need for dialysis. Only $14 \%$ of patients required permanent pacing, and most patients had only trivial or mild paravalvular leak after ViV-TAVI. Although most ViV-TAVI procedures were performed urgently in highly symptomatic patients with high pre-procedural risk scores, the mean hospital stay was short (significantly shorter than after redo-AVR in younger patients with fewer comorbidities). This outcome reflects 
the dramatic improvement in the clinical status of these older, frailer patients after ViV-TAVI. This clinical improvement was striking and immediate, with all surviving patients discharged back to their own homes early after ViV-TAVI, with ability to be independent in all activities of daily living. At 1 year, all patients reported continued symptomatic improvement, and echocardiography demonstrated no evidence of late valve migration, structural valve dysfunction, or patient-prosthesis mismatch.

\section{Choice of Device Type}

All patients received a self-expanding transcatheter device, and multiple device sizes were implanted. Although we had access to balloon-expandable devices, we felt that a self-expanding device offered certain advantages. First, such a device reduces the risk of annular or sinus rupture. In our experience, stentless valves, particularly the homograft roots, often have eggshell-type calcification of the annulus that frequently extends up into the aortic sinuses. We felt that the balloon-expandable device might be more likely to cause annular or sinus disruption in these circumstances. Given this concern, we felt more comfortable in oversizing the self-expanding device to a greater degree than we would have with a balloon-expandable device. This oversizing clearly had advantages in the setting of the anatomy of failing stentless valves with a lack of bulky calcified leaflets in the vast majority of cases. Second, we believe using a self-expanding device implanted at the optimal height carried a lower risk of coronary obstruction in this setting, compared with the balloon-expandable device.

Third, 10 of 22 patients had 1 aortic annular diameter of $\leq 21 \mathrm{~mm}$, as measured on MSCT. With these dimensions, we felt the supra-annular design of the self-expanding device was more likely to result in lower gradients than a balloon-expandable device; particularly because we did not have access to the SAPIEN XT valve (Edwards LifeSciences, Irvine, Calif), size 20-mm, during the time course of this study. Fourth, in the setting of suboptimal device positioning, it is usually easy to implant a second self-expanding valve within the first, in a more optimal position. In general, device malpositioning with a balloonexpandable valve tends to be more problematic, with displacement of the valve into the aorta or ventricle. Finally, given that we have more experience with the self-expanding system, we undoubtedly had a greater degree of comfort in using this device in this complex setting.

\section{Level of Implantation and Valve Sizing}

In an attempt to reduce the potential complications of device migration, device embolization, and coronary obstruction associated with ViV-TAVI, ${ }^{17,20,21,26}$ all patients in our study underwent meticulous pre-procedural planning with respect to valve sizing with MSCT and 3-dimensional transoesophageal echocardiography. In an attempt to define the "annular" level, ${ }^{27}$ the previous surgical operation notes were consulted in each case to appreciate the specific implantation technique appropriate for each individual patient.

A major difficulty is the lack of guidelines for device sizing in ViV-TAVI for a failing stentless bioprosthesis. The manufacturer's ViV sizing guide provides recommendations for native aortic valve stenosis, and the ViV sizing $\mathrm{app}^{28}$ provides sizing guidance for only stented, not stentless, aortic valves. All our patients had severe aortic regurgitation, owing to stentless leaflet degeneration, and most lacked leaflet or annular calcification. Thus, we felt that implementing the manufacturer's recommendations in these instances would have resulted in undersizing of the prospective device, increasing the risk of device migration and paravalvular leak. Instead, we calculated the unconstrained perimeter of the available devices (Table 1) and implanted device that was oversized in terms of the device perimeter, compared with the annular perimeter in 19 of $22(86 \%)$ patients.

Using these measures, we were able to implant a single transcatheter device during a single procedure into the correct anatomic location, with absent or trivial paravalvular leak in these 19 patients. Other than the initial emergency patient, and the patient who had valve embolization resulting from a technical error, mild-to-moderate paravalvular leak was a feature in only 1 patient, in whom a single undersized ViV-TAVI device had been implanted. Device migration (defined by VARC-2 as movement of the valve prosthesis upward or downward within the aortic annulus from its initial position, with or without consequences after initial correct positioning ${ }^{24}$ ) requiring a second TAVI during the same procedure was a feature in only 3 patients, and all 3 of these patients lacked any valvular calcification and demarcation of a clear landing zone. Other possibilities are suboptimal device sizing, owing to lack of calcification on MSCT, or inaccurate reporting of stentless valve sizing at the time of the original surgery.

Future technology, including the use of advanced imaging software (with fusion of MSCT, 3-dimensional transoesophageal echocardiography, and fluoroscopy) may overcome these difficulties and reduce the incidence of valve migration in ViV-TAVI procedures by allowing more-precise measurement of aortic annular dimensions and definition of the aortic "annular" landing zone. Moreover, introduction of fully recapturable and repositionable devices during ViV-TAVI for stentless bioprostheses may further mitigate the incidence of valve maldeployment by allowing recapture of a malpositioned device, even during the later phases of deployment. Given that valve migration, embolization, and coronary obstruction remain potential serious complications of ViV-TAVI, we advocate that the procedure be performed in a high-volume tertiary-referral center where surgeons are experienced in performing TAVI for a failing stentless bioprosthesis. 


\section{Limitations}

The primary aim of this study was to report procedural and midterm outcomes of patients undergoing ViV-TAVI for a failing stentless bioprosthesis at a single institution. For comparison, we retrospectively compared our results with those from patients undergoing redo AVR for a failing stentless bioprosthesis at the same institution during the same study period. An interesting comparison would be that of our findings with baseline characteristics and outcomes of patients with a failing stentless aortic bioprosthesis who had neither ViV-TAVI nor redo AVR, but complete retrospective data were not available to us in this group of patients.

\section{CONCLUSIONS}

Valve-in-valve TAVI utilizing a self-expanding TAVI device is an effective way to treat failing stentless aortic bioprostheses. Many patients present in a decompensated clinical condition. These implants can be used safely and successfully with extraordinarily rapid improvement in the patient's condition. However, device sizing and positioning are extremely challenging aspects of the procedure. Detailed pre-procedural planning, including use of MSCT scanning, rapid pacing during deployment, and 2- and 3-dimensional transoesophageal echocardiography to facilitate deployment accuracy, are important. Despite use of these aids, suboptimal placement remains an issue, so these procedures likely should be referred to high-volume tertiary centers, with staff experienced in self-expanding valve technology.

\section{Conflict of Interest Statement}

Neil Moat is a consultant to Medtronic Inc (Minneapolis, Minn). All other authors have nothing to disclose with regard to commercial support.

\section{References}

1. Jones JM, O'Kane H, Gladstone DJ, Sarsam MA, Campalani G, MacGowan SW, et al. Repeat heart valve surgery: risk factors for operative mortality. $J$ Thorac Cardiovasc Surg. 2001;122:913-8.

2. Ruel M, Kulik A, Rubens FD, Bédard P, Masters RG, Pipe AL, et al. Late incidence and determinants of reoperation in patients with prosthetic heart valves. Eur J Cardiothorac Surg. 2004;25:364-70.

3. Kirsch M, Nakashima K, Kubota S, Houël R, Hillion ML, Loisance D. The risk of reoperative heart valve procedures in octogenarian patients. $J$ Heart Valve Dis. 2004;13:991-6.

4. Maganti M, Rao V, Armstrong S, Feindel CM, Scully HE, David TE. Redo valvular surgery in elderly patients. Ann Thorac Surg. 2009;87:521-5.

5. Leontyev S, Borger MA, Davierwala P, Walther T, Lehmann S, Kempfert J, et al. Redo aortic valve surgery: early and late outcomes. Ann Thorac Surg. 2011;91: 1120-6.

6. Webb JG, Wood DA, Ye J, Gurvitch R, Masson JB, Rodés-Cabau J, et al. Transcatheter valve-in-valve implantation for failed bioprosthetic heart valves. $\mathrm{Circu}$ lation. 2010;121:1848-57.

7. Gotzmann M, Mügge A, Bojara W. Transcatheter aortic valve implantation for treatment of patients with degenerated aortic bioprosthesis - valve-in-valve technique. Catheter Cardiovasc Interv. 2010;76:1007-8.

8. Kawaja MZ, Haworth P, Ghuran A, Lee L, de Belder A, Hutchinson N, et al. Transcatheter aortic valve implantation for stenosed and regurgitant aortic valve bioprostheses. CoreValve for failed bioprosthetic aortic valve replacements. J Am Coll Cardiol. 2010;55:91-101.
9. Gurvitch R, Cheung A, Ye J, Wood DA, Willson AB, Toggweiler S, et al. Transcatheter valve-in-valve implantation for failed surgical bioprosthetic valves. $J$ Am Coll Cardiol. 2011;58:2196-209.

10. Piazza N, Bleiziffer S, Brockmann G, Hendrick R, Deutsch MA, Opitz A, et al. Transcatheter aortic valve implantation for failing surgical aortic bioprosthetic valve: from concept to clinical application and evaluation (part 1). JACC Cardiovasc Interv. 2011;4:721-32.

11. Piazza N, Bleiziffer S, Brockmann G, Hendrick R, Deutsch MA, Opitz A, et al. Transcatheter aortic valve implantation for failing surgical aortic bioprosthetic valve: from concept to clinical application and evaluation (part 2). JACC Cardiovasc Interv. 2011;4:733-42.

12. Bedogni F, Laudisa ML, Pizzocri S, Tamburino C, Ussia GP, Petronio AS, et al. Transcatheter valve-in-valve implantation using Corevalve Revalving System for failed surgical aortic bioprostheses. JACC Cardiovasc Interv. 2011;4:1228-34.

13. Eggebrecht H, Schäfer U, Treede H, Boekstegers P, Babin-Ebell J, Ferrari M, et al. Valve-in-valve transcatheter aortic valve implantation for degenerated bioprosthetic heart valves. JACC Cardiovasc Interv. 2011;4:1218-27.

14. Linke A, Woitek F, Merx M, Schiefer C, Möbius-Winkler S, Holzey D, et al. Valve-in-valve implantation of medtronic corevalve prosthesis in patients with failing bioprosthetic aortic valves. Circ Cardiovasc Interv. 2012;5:689-97.

15. Conradi L, Seiffert M, Treede H, Silaschi M, Baldus S, Schirmer J, et al. Transcatheter aortic valve implantation versus surgical aortic valve replacement: a propensity score analysis in patients at high surgical risk. J Thorac Cardiovasc Surg. 2012;143:64-71.

16. Webb JG, Dvir D. Transcatheter aortic valve replacement for bioprosthetic aortic valve failure: the valve-in-valve procedure. Circulation. 2013;127:2542-50.

17. Lange R, Piazza N. Transcatheter aortic valve-in-surgical aortic valve implantation: current status and future perspectives. Eur J Cardiothorac Surg. 2013;44:403-6.

18. Mylotte D, Lange R, Martucci G, Piazza N. Transcatheter heart valve implantation for failing surgical bioprostheses: technical considerations and evidence for valve-in-valve procedures. Heart. 2013;99:960-7.

19. Thlberg L, Nissen H, Nielsen NE, Rück A, Busund R, Klaarborg KE, et al. Early clinical outcome of aortic transcatheter valve-in-valve implantation in the Nordic countries. J Thorac Cardiovasc Surg. 2013;146:1047-54.

20. Dvir D, Webb JG, Bleiziffer S, Pasic M, Waksman R, Kodali S, et al. Valve-inValve International Data Registry investigators. Transcatheter aortic valve implantation in failed bioprosthetic surgical valves. JAMA. 2014;312:162-70.

21. Dvir D, Webb J, Brecker S, Bleiziffer S, Hildick-Smith D, Colombo A, et al. Transcatheter aortic valve replacement for degenerative bioprosthetic surgical valves: results from the global valve-in-valve registry. Circulation. 2012;126: 2335-44.

22. Chan PH, Di Mario C, Davies SW, Kelleher A, Trimlett R, Moat N. Transcatheter aortic valve implantation in degenerate failing aortic homograft root replacements. J Am Coll Cardiol. 2011;58:1729-30.

23. Zamorano JL, Gonçalves A, Lang R. Imaging to select and guide transcatheter aortic valve implantation. Eur Heart J. 2014;35:1578-87.

24. Kappetein AP, Head SJ, Généreux P, Piazza N, van Mieghem NM, Blackstone EH, et al. Updated standardized endpoint definitions for transcatheter aortic valve implantation: the Valve Academic Research Consortium-2 consensus document (VARC-2). J Thorac Cardiovasc Surg. 2013;145:6-23.

25. Akins CW, Miller DC, Turina MI, Kouchoukos NT, Blackstone EH, Grunkemeier GL, et al. Councils of the American Association for Thoracic Surgery, Society of Thoracic Surgeons, European Association for Cardio-Thoracic Surgery, Ad Hoc Liason Committee for Standardizing Definitions of Prosthetic Heart Valve Morbidity. Guidelines for reporting mortality and morbidity and cardiac valve interventions. J Thorac Cardiovasc Surg. 2008;135:732-8.

26. Bapat V, Davies W, Attia R, Hancock J, Bolter K, Young C, et al. Use of balloon expandable transcatheter valves for valve-in-valve implantation in patients with degenerative stentless aortic bioprosthesis: technical considerations and results. $J$ Thorac Cardiovasc Surg. 2014;148:917-24.

27. Bapat V, Adams B, Attia R, Noorani A, Thomas M. Neo-annulus: a reference plane in a surgical heart valve to facilitate a valve-in-valve procedure. Catheter Cardiovasc Interv. 2015;85:685-91.

28. European Association for Cardio-Thoracic Surgery. Valve-in-valve app wins 2013 EACTS Techno College Innovation Award. Available at: http://www. eacts.org/media/132914/eacts-2013-sundaylr.pdf). Accessed November 2014.

Key Words: Degenerate stentless bioprosthesis, valve-invalve, transcatheter valve implantation, outcome 